\title{
Percutaneous closure of coronary artery fistula: long-term follow-up results
}

\author{
Erdogan Ilkay ${ }^{1}$, Ozlem Ozcan Celebi ${ }^{1}$, Fehmi Kacmaz ${ }^{2}$, Ozcan Ozeke ${ }^{3}$ \\ ${ }^{1}$ Department of Cardiology, Medicana International Ankara Hospital, Ankara, Turkey \\ ${ }^{2}$ Department of Cardiology, OSM Ortadoğu Hospital, Sanliurfa, Turkey \\ ${ }^{3}$ Department of Cardiology, Turkiye Yuksek Ihtisas Hospital, Ankara, Turkey
}

Postep Kardiol Inter 2015; 11, 4 (42): 318-322

DOI: $10.5114 /$ pwki.2015.55603

\begin{abstract}
A bstract
Introduction: Coronary artery fistula consists of abnormal congenital connections between a coronary artery and cardiac chambers, a coronary vessel or an intrathoracic vessel that can be complicated by intracardiac shunts, endocarditis, myocardial infarction, or coronary aneurysms. Recent reports have emphasized the efficacy of percutaneous transcatheter techniques as an alternative to surgical closure, but the reported experience is relatively limited.

Aim: To assess angiographic outcomes in a series of 20 patients who underwent transcatheter closure of coronary artery fistula.

Material and methods: We evaluated all patients presenting with significant coronary artery fistula and undergoing transcatheter closure with coils and a vascular plug between March 2008 and June 2012.

Results: There were 20 patients (14 men; mean age: $53 \pm 8$ years) with coronary artery fistula. Fistula diameter ranged from 4 to $12 \mathrm{~mm}$; an average of three coils were used in the percutaneous procedure. Post-deployment angiograms demonstrated complete occlusion in all patients. The patients were followed up for $4 \pm 1.6$ years. The control coronary computed tomographic angiography was performed in the sixth month and no patients had recanalization of the embolized vessel.

Conclusions: Percutaneous closure of coronary artery fistula is a safe and effective treatment modality.
\end{abstract}

Key words: coronary artery fistula, percutaneous closure, coronary computed tomographic angiography.

\section{Introduction}

Coronary artery fistula (CAF) is most commonly congenital in origin and rarely of iatrogenic origin. It is an uncommon anomaly characterized by an abnormal connection between the coronary arteries and cardiac chambers or nearby vessels bypassing the usual myocardial capillary network. The majority of CAF are small, are detected incidentally in about $0.1 \%$ of adult patients undergoing routine coronary angiography and do not require intervention [1].

The clinical presentation of congenital CAF may vary considerably, depending on its anatomy and the size of the fistulous connection to the left or right side of the heart and its flow reserve. Treatment of CAF is indicated for symptomatic patients and for those asymptomatic patients with significant shunt or large fistulas that create a risk for future complications, such as infective endocarditis, pulmonary hypertension or heart failure [1]. Traditionally, surgery has been the main therapeu- tic method for the closure of CAF, with proven efficacy and safety, but transcatheter closure approaches have emerged as a less invasive strategy and are nowadays considered a valuable alternative to surgical correction, with similar effectiveness, morbidity and mortality [2-8]. However, information on the long-term outcome after percutaneous CAF closure is limited.

Aim

The purpose of the present article is to evaluate the immediate and long-term follow-up results of transcatheter closure of CAF.

\section{Material and methods}

Twenty patients with CAF who underwent catheterization between March 2008 and June 2012 were enrolled in the study. Patients with additional complex cardiac disease requiring surgical management and those with

\section{Corresponding author:}

Ozlem Ozcan Celebi, Department of Cardiology, Medicana International Ankara Hospital, 06100 Ankara, Turkey, phone: +90 3122929292,

e-mail: drozlemoz79@yahoo.com

Received: 7.02.2015, accepted: 7.04.2015. 
a small CAF found incidentally during echocardiography or catheterization were excluded. All patients underwent a cardiac evaluation, including medical history, physical examination, electrocardiogram and transthoracic echocardiogram. Written informed consent was obtained from all patients before the procedure.

Once access was secured via the femoral artery, an intravenous heparin bolus (60 to $100 \mathrm{U} / \mathrm{kg}$ ) was given to all patients. After obtaining hemodynamic data, the coronary arteries were engaged selectively using various diagnostic guidewires and catheters. Hand injection of contrast allowed visualization of coronary anatomy, and location of CAF including origin and drainage sites. The left to right shunting was assessed by measurement of pulmonary to systemic flow ratio data (QP:QS) gathered from diagnostic catheterization. Delivery catheters were positioned either directly from the coronary ostia into the CAF, typically with small French size catheters and coronary guidewires. This allowed for deep intubation, permitting accurate coil delivery to the desired target within the fistula. We used embolization devices including standard coils, controlled-release coils, microcoils (standard, GDC or IDC) and Amplatzer vascular plug II. The devices and their delivery systems have been described in detail previously [9-14]. Selective coronary angiography was performed immediately after device deployment. All the procedures were performed by the same operator. Patients were not routinely treated with oral anticoagulation or antiplatelet therapy following the procedure. Control multidetector computed tomographic (MDCT) angiography was performed in the sixth month and first year follow-up.

\section{Results}

Twenty patients (14 men; mean age: $53 \pm 8$ years) with symptomatic CAF underwent transcatheter closure with coils and Amplatzer vascular plug II. The most common presenting symptom was chest pain with exercise dyspnea (75\%). Five patients had a fistula originating from the first diagonal artery draining into the pulmonary artery, 2 patients had a fistula draining into the coronary sinus from the posterior descending artery, and 1 patient had a fistula from the first obtuse marginal branch to the right ventricular outflow tract. The fistula most commonly (9 patients) originated from the right coronary artery draining into the right cardiac chambers (atrium-ventricle). Two patients had fistulas originating from the left circumflex artery and draining to the bronchial artery. One had a large fistula originated from the right coronary artery draining the vena cava superior. Mean QP:QS ratio was 1.9 (range: 1.6-2.5).

Fistula diameter ranged from 4 to $12 \mathrm{~mm}$; an average of 3.3 coils were used in 18 patients and Amplatzer vascular plug $I I$ in 2 patients. Post-deployment angiograms taken $30 \mathrm{~min}$ after closure demonstrated com- plete occlusion in all patients. Complete atrioventricular block occurred in 1 patient. In this patient, the fistula was between the right coronary artery and the right atrium. During implantation of the coil, AV block developed abruptly. In the sixth month and first year follow-up, coronary computed tomographic angiography was performed and no recanalization of the embolized vessel was found (Figure 1). The mean follow-up period was $4 \pm 1.6$ years; all patients were asymptomatic and no late complications or deaths were recorded. Baseline and follow-up clinical and functional data are shown in Table I. Six patients with palpitation at baseline had sinus tachycardia. Patients with palpitation after the procedure had normal sinus rhythm.

\section{Discussion}

The first transcatheter closure of congenital CAF was performed in 1983 by Reidy et al., and it has increasingly become the first line therapy in anatomically suitable cases [15]. This technique has advantages over surgery that include: lower cost, shorter recovery time and duration of hospitalization, and avoidance of thoracotomy and cardiopulmonary bypass. Our results have confirmed previous evidence suggesting that the percutaneous closure of CAF with coil placement was a safe and effective treatment modality [2-8]. Prognosis of our patients after the closure procedure is good in long-term follow-up results.

Treatment of CAF is indicated for symptomatic patients and for those asymptomatic patients with significant shunt or large fistulas that create a risk for future complications, such as infective endocarditis, pulmonary hypertension or heart failure [1]. Most patients are asymptomatic; symptoms mostly depend on underlying cardiac anatomy and the size of the CAF. With a tendency for symptoms to develop over time, symptomatic CAF may present for the first time in adulthood. The 2008 American College of Cardiology/American Heart Association guidelines for the management of adults with congenital heart disease recommend closure of all large CAF regardless of symptomatology using transcatheter or surgical techniques, and call for closure of small to moderate fistulas only in the presence of symptoms (including ischemia, arrhythmia, and unexplained systolic or diastolic dysfunction). They do not recommend closure of small, asymptomatic CAF [16]. Mavroudis et al. recommend elective coil occlusion in patients who satisfy the following criteria: absence of multiple fistulas, a single narrow drainage site, absence of large branch vessels, and safe accessibility to the coronary artery supplying the fistula [17]. Development of catheter and coil technology has made it a safe procedure [18-21]. Techniques previously described for transcatheter closure of CAF in adults include the use of various types of detachable occlusion coils, Amplatzer vascular plugs, Amplatzer umbrella devices, detachable balloons, covered stents, and 

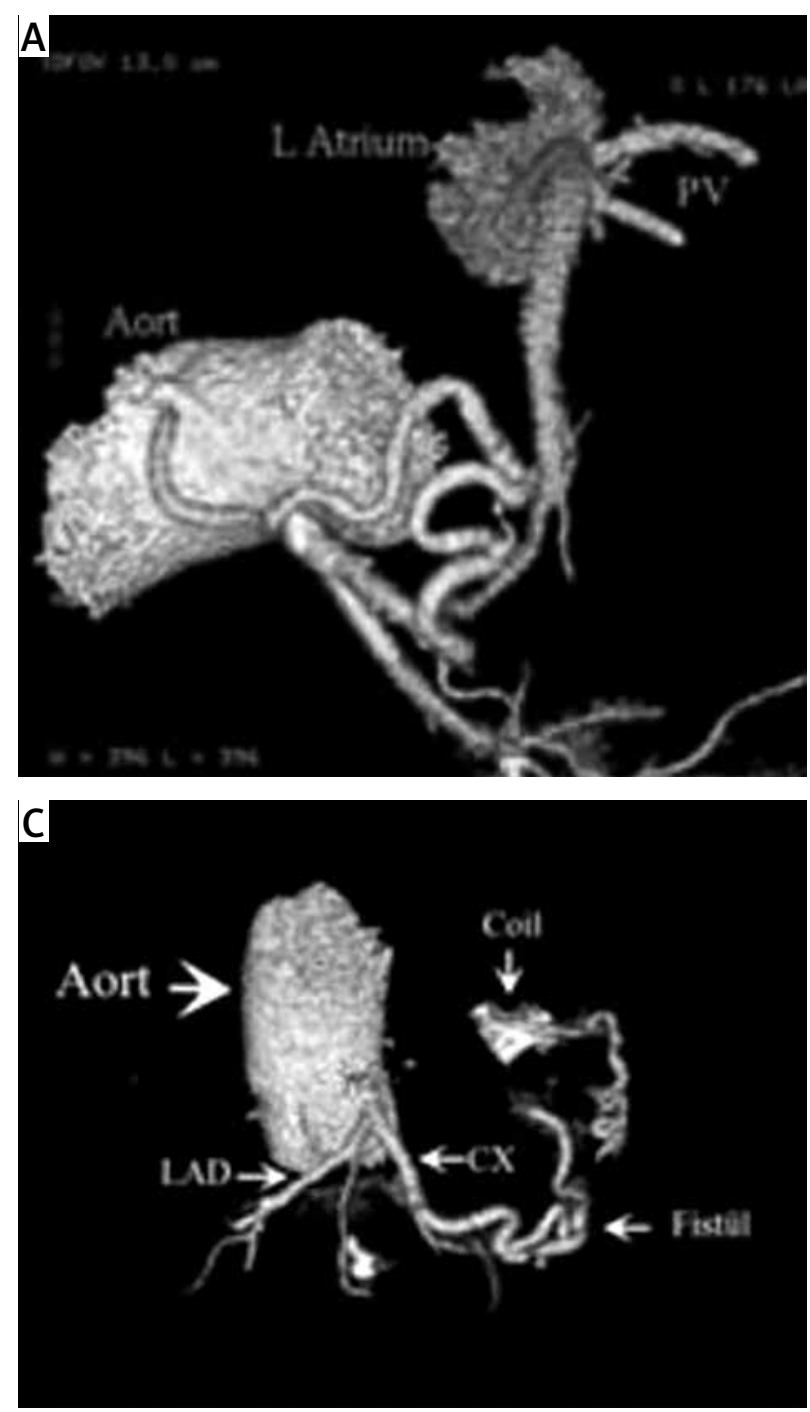

histoacryl resin, while the vast majority of the fistulas were closed using microcoils [22-29].

The procedural complications reported in the literature include transient ischemic changes, unretrieved de-

Table I. Baseline and 6-month follow-up clinical findings of the study population

\begin{tabular}{lccc} 
Variable & $\begin{array}{c}\text { Baseline } \\
(n=20)\end{array}$ & $\begin{array}{c}\text { Follow-up } \\
(n=20)\end{array}$ & Value of $p$ \\
\hline Angina pectoris: & $8(40)$ & $2(10)$ & $<0.05$ \\
\hline NYHA class 1 & $4(50)$ & $2(100)$ & \\
\hline NYHA class 2 & $3(37.5)$ & 0 & \\
\hline NYHA class 3 & $1(12.5)$ & 0 & $<0.01$ \\
\hline NYHA class 4 & 0 & 0 & $<0.01$ \\
\hline Dyspnea & $15(75)$ & $3(15)$ & $<0.001$ \\
\hline Palpitations & $11(55)$ & $6(30)$ & \\
\hline $\begin{array}{l}\text { Positive treadmill } \\
\text { stress test }\end{array}$ & $4(20)$ & 0 & \\
Results presented as $n$ (\%). & &
\end{tabular}

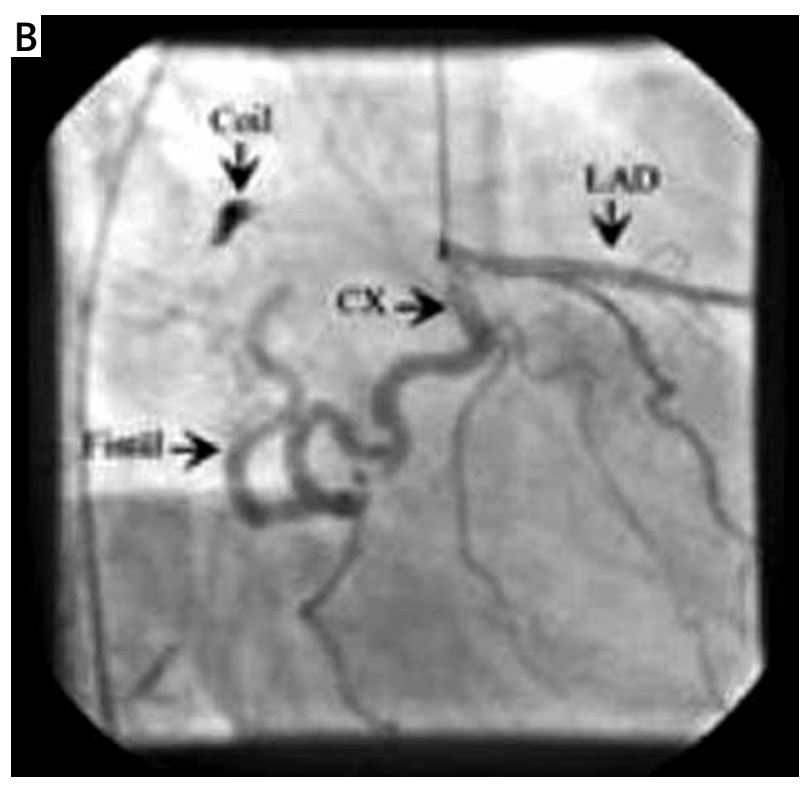

Figure 1. A - Multislice computed tomography shows the coronary artery fistula between the left circumflex (LCX) artery and bronchial artery. B - Coronary angiography (antero-posterior caudal view) demonstrates the coil embolization and closure of the fistula. C - Multislice computed tomography shows the closure of the fistula after coil embolization

vice embolization, fistula dissection, myocardial infarction, transient atrial arrhythmia and death. In our group AV block developed during the coil embolization procedure. Complete AV block has not been reported to date. However, coil embolization is a rare entity and unexpected complications may occur. In this patient we suggest that the fistula had side branches to the AV node. "Jailing" these side branches resulted in complete AV block and we implanted a permanent pacemaker.

There are cases reported in the literature in which lowdose aspirin and oral anticoagulant therapy addition for prophylaxis of thrombosis were used if the coronary flow was sluggish. However, there is limited data available regarding the risk of coronary thrombosis in this group, and the benefits are still controversial [30, 31]. Thus, we did not routinely treat the patients with oral anticoagulation or antiplatelet therapy following the procedure.

During follow-up, recanalization of the fistula was also reported [4-7]. Given the presence of recanalization risk after percutaneous fistula closure, it is important to routinely follow these patients after fistula closure even 
if they remain asymptomatic. In this study we evaluated the role of multislice computed tomography for the follow-up of CAFs [32]. The MSCT provides detailed information regarding the location of the device with respect to surrounding anatomic structures and reveals anomalies not evident in transesophageal echocardiography (TEE) [2]. However, MDCT is not a suitable imaging method in patients who have CAF originating in the distal segment of a coronary artery with small vascular structure and coursing between coronary arteries and cardiac chambers.

In our study we used an antegrade approach. In the literature, it was reported that a retrograde approach has some advantages over the antegrade approach [33]. The retrograde approach has an advantage in cases when the fistula is draining near the coronary sinus. None of our patients was of this type, so we preferred the antegrade approach.

The limitation of the present report is the small sample of patients. However, because of the low incidence of CAF, and treatment only being indicated in symptomatic patients, it is difficult to achieve a more representative sample of patients.

\section{Conclusions}

Transcatheter closure using interventional devices must be considered as an alternative treatment in selected cases of isolated CAF depending on the anatomy of the fistula, the presence or absence of associated defects and the experience of the interventional cardiologists and surgeons.

\section{Conflict of interest}

The authors declare no conflict of interest.

\section{References}

1. Vavuranakis M, Bush CA, Boudoulas H. Coronary artery fistulas in adults: incidence, angiographic characteristics, natural history. Cathet Cardiovasc Diagn 1995; 35: 116-20.

2. Kacmaz F, Isiksalan Ozbulbul N, Alyan O, et al. Imaging of coronary artery fistulas by multidetector computed tomography: is multidetector computed tomography sensitive? Clin Cardiol 2008; 31: 41-7.

3. Oto A, Aytemir K, Çil B, et al. Percutaneous closure of coronary artery fistulae in adults with intermediate term follow-up results. J Interv Cardiol 2011; 24: 216-22.

4. Jama A, Barsoum M, Bjarnason $H$, et al. Percutaneous closure of congenital coronary artery fistulae: results and angiographic follow-up. JACC Cardiovasc Interv 2011; 4: 814-21.

5. Armsby LR, Keane JF, Sherwood MC, et al. Management of coronary artery fistulae. Patient selection and results of transcatheter closure. J Am Coll Cardiol 2002; 39: 1026-32.

6. Zhu XY, Zhang DZ, Han XM, et al. Transcatheter closure of congenital coronary artery fistulae: immediate and long-term follow-up results. Clin Cardiol 2009; 32: 506-12.
7. Okubo M, Nykanen D, Benson LN. Outcomes of transcatheter embolization in the treatment of coronary artery fistulas. Cathet Cardiovasc Interv 2001; 52: 510-17.

8. Collins N, Mehta R, Benson L, et al. Percutaneous coronary artery fistula closure in adults: technical and procedural aspects. Catheter Cardiovasc Interv 2007; 69: 872-80.

9. Behera SK, Danon S, Levi DS, et al. Transcatheter closure of coronary artery fistulae using the Amplatzer duct occluder. Catheter Cardiovasc Interv 2006; 68: 242-8.

10. Cheung Y, Leung MP, Chau K. Transcatheter closure of persistent arterial ducts with different types of coils. Am Heart J 2001; 141: 87-91.

11. Liang CD, Ko SF. Midterm outcome of percutaneous transcatheter coil occlusion of coronary artery fistula. Pediatr Cardiol 2006; 27: 557-63.

12. Thanopoulos BV, Rigby ML, Karanasios E, et al. Transcatheter closure of perimembranous ventricular septal defects in infants and children using the Amplatzer perimembranous ventricular septal defect occluder. Am J Cardiol 2007; 99: 984-9.

13. Fischer G, Apostolopoulou SC, Rammos S, et al. Transcatheter closure of coronary arterial fistulas using the new Amplatzer vascular plug. Cardiol Young 2007; 17: 283-7.

14. Trehan V, Yusuf J, Mukhopadhyay S, et al. Transcatheter closure of coronary artery fistulas. Indian Heart J 2004; 56: 132-9.

15. Reidy JF, Sowton E, Ross DN. Transcatheter occlusion of coronary to bronchial anastomosis by detachable balloon combined with coronary angioplasty at same procedure. Br Heart J 1983; 49: 284-7.

16. Warnes CA, Williams RG, Bashore TM, et al. ACC/AHA 2008 guidelines for the management of adults with congenital heart disease: a report of the American College of Cardiology/American Heart Association Task Force on Practice Guidelines (Writing Committee to Develop Guidelines for the Management of Adults with Congenital Heart Disease). J Am Coll Cardiol 2008; 52: e1-121.

17. Mavroudis C, Backer CL, Rocchini AP, et al. Coronary artery fistulas in infants and children: a surgical review and discussion of coil embolization. Ann Thorac Surg 1997; 63: 1235-42.

18. Justo RN, Slaughter RE, Whight CM, et al. Transcatheter embolisation of coronary artery fistulae. Heart Lung Circ 2001; 10 : 53-7.

19. Bonello L, Com O, Gaubert JY, et al. Covered stent for closure of symptomatic plexus-like coronary fistula. Int J Cardiol 2006; 109: 408-10.

20. Subramanyan R, Agrawal A, Abhyankar A. Transcatheter closure of a large coronary artery fistula with Amplatzer duct occluder: a new approach. Indian Heart J 2001; 53: 493-5.

21. Krabill KA, Hunter DW. Transcatheter closure of congenital coronary arterial fistula with a detachable balloon. Pediatr Cardiol 1993; 14: 176-8.

22. Reidy JF, Anjos RT, Qureshi SA, et al. Transcatheter embolization in the treatment of coronary artery fistulas. J Am Coll Cardiol 1991; 18: 187-92.

23. Sreedharan M, Prasad G, Barooah B, et al. Vortex coil embolisation of coronary artery fistula. Int J Cardiol 2004; 94: 323-4.

24. Sadiq M, Wilkinson JL, Qureshi SA. Successful occlusion of a coronary arteriovenous fistula using an Amplatzer duct occluder. Cardiol Young 2001; 11: 84-7.

25. Perry SB, Rome J, Keane JF, et al. Transcatheter closure of coronary artery fistulas. J Am Coll Cardiol 1992; 20: 205-9. 
26. Hoffer E, Materne P, Beckers J, et al. Endovascular treatment of a coronary artery bypass graft to right ventricle fistula with balloon embolization. Int J Cardiol 2006; 112: e50-2.

27. Petrie MC, Peels JO, Jessurun G. The role of covered stents: more than an occasional cameo? Catheter Cardiovasc Interv 2006; 68: 21-6.

28. Karagoz T, Celiker A, Cil B, et al. Transcatheter embolization of a coronary fistula originating from the left anterior descending artery by using n-butyl 2-cyanoacrylate. Cardiovasc Intervent Radiol 2004; 27: 663-5.

29. Villavicencio R, Marenco R, Zenteno MA, et al. Selective coronary artery fistula embolization with hystoacryl during percutaneous coronary angioplasty. J Invasive Cardiol 2003; 15: 80-3.

30. Reith S, Reinartz SD, Burgmaier M, et al. Efficacy and safety of transcatheter coil embolization in congenital coronary artery fistulas guided by preinterventional cardiac computed tomography. Coron Artery Dis 2013; 24: 422-30.

31. McMahon CJ, Nihill MR, Kovalchin JP, et al. Coronary artery fistula. Management and intermediate term outcome after transcatheter coil occlusion. Tex Heart Inst J 2001; 28: 21-5.

32. Kaçmaz F, Maden O, Erbay AR, et al. A very rare cause of continuous murmur and coronary ischemia: high-flow coronary-to-pulmonary artery fistula. Turk Kardiyol Dern Ars 2008; 36: 476-8.

33. Kassaian SE, Alidoosti M, Sadeghian H, et al. Transcatheter closure of a coronary fistula with an Amplatzer vascular plug: should a retrograde approach be standard? Tex Heart Inst 2008; 35: 58-61. 